\title{
Abnormal uterine bleeding types according to the PALM-COEIN FIGO classification in a medically underserved American community
}

\author{
(D) Alexander Sabre1, (D) Lisa Serventi ${ }^{1}$, (D) Dilfuza Nuritdinova ${ }^{1}$, (D) Antonio Schiattarella ${ }^{2}$, (D) Giovanni Sisti ${ }^{1}$ \\ 1Department of Obstetrics and Gynecology, New York City Health and Hospitals/Lincoln, New York, United States of \\ America \\ 2Department of Woman, Child and General and Specialized Surgery, University of Campania "Luigi Vanvitelli", Naples, Italy
}

\section{Abstract}

Objective: To describe the distribution of abnormal uterine bleeding (AUB) type according to the polyp (AUB-P); adenomyosis (AUB-A); leiomyoma (AUB-L); malignancy and hyperplasia (AUB-M); coagulopathy (AUB-C); ovulatory dysfunction (AUB-O); endometrial (AUB-E); iatrogenic (AUB-I); and not yet classified International Federation of Gynecology and Obstetrics classification system in a medically underserved American inner-city population. Our secondary objective was to find an association between risk factors and type of AUB.

Material and Methods: We conducted a descriptive cross-sectional analysis at our outpatient women's health clinic located in the Bronx, New York City, from November 2016 to December 2019.

Results: Among 390 patients, the most common AUB type was AUB-L ( $\mathrm{n}=185,47.4 \%)$, followed AUB-P ( $\mathrm{n}=100,25.6 \%)$, AUB-A ( $\mathrm{n}=55,14.1 \%)$, AUB-O ( $n=19,4.9 \%)$, AUB-M ( $n=15,3.8 \%)$, AUB-E $(n=14,3.6 \%)$ and AUB-I $(n=2,0.5 \%)$. Race was distributed as follows: Hispanic $(68.2 \%)$, Black (25.9\%), Caucasian (3.3\%), and Asian (2.1\%). Comorbidities included hypertension (36.4\%), diabetes (15.6\%), and thyroid disease (6.9\%). The median age at diagnosis was significantly higher in AUB-M (59 years old, p<0.001), AUB-P (52.5 years old, p<0.001), AUB-E (51.5 years old, $\mathrm{p}=0.001$ ) compared to AUB-L (46 years old). The median body mass index (BMI) was significantly higher in AUB-E (34.2 kg/m², $\mathrm{p}=0.048)$ and AUB-O $\left(32.6 \mathrm{~kg} / \mathrm{m}^{2}, \mathrm{p}=0.038\right)$ compared to AUB-L $\left(30 \mathrm{~kg} / \mathrm{m}^{2}\right)$. Race was equally distributed among the AUB types. AUB-M (66.6\%, $\left.\mathrm{p}=0.002\right)$, AUB-E (57.1\%, $\mathrm{p}=0.022)$, AUB-P (47\%, p < 0.001), and AUB-A (30.8\%, p<0.001), had statistically significantly more cases of hypertension compared to AUB-L (28.1\%). AUB-P (27\%, p<0.001), AUB-M (26.6\%, p=0.025), AUB-E (35.7\%, p=0.001) and AUB-A (9\%, p<0.001) had more patients with diabetes mellitus (DM) than AUB-L (3.3\%).

Conclusion: In an American population of medically underserved patients, the most common cause of AUB was leiomyoma and the most common race was Hispanic. Women with AUB-L were younger, with lower BMI, and with fewer cases of hypertension and DM when compared to other types of AUB. (J Turk Ger Gynecol Assoc 2021; 22: 91-6)

Keywords: AUB, PALM-COEIN, abnormal uterine bleeding, myoma, polyp

Received: 02 December, 2020 Accepted: 16 February, 2021

\section{Introduction}

Abnormal uterine bleeding (AUB) is a common medical condition experienced by approximately one-third of women in their lifetime $(1,2)$. AUB is a broad term that describes irregularities in the menstrual cycle involving frequency, duration, and volume of flow outside of pregnancy (3). AUB is diagnosed in both inpatient and outpatient settings, accounting for up to $70 \%$ of consultations with gynecologists (4). The International Federation of Gynecology and Obstetrics (FIGO) created a reproducible classification system for AUB in 2011 (5). The nomenclature for this spectrum is commonly known by the acronym polyp; adenomyosis; leiomyoma; malignancy and hyperplasia; coagulopathy; ovulatory dysfunction; endometrial; 
iatrogenic; and not yet classified (PALM-COEIN). The etiologies correlate to structural disorders such as endometrial/uterine polyp (P), adenomyosis (A), leiomyoma (L), malignant lesions of the uterine body (M); and non-structural disorders such as coagulopathies (C), ovulatory dysfunction (O), endometrial dysfunction (E), iatrogenic (I), and not yet classified (N) (5).

AUB can lead to severe anemia and other medical complications and can significantly impact the patients' quality of life. Several medical and surgical therapies are available, and they are personalized depending on the acuity and severity of the AUB. Hormonal medications, endometrial ablation, hysteroscopic surgery, hysterectomy, and uterine artery embolization are some of the most commonly employed therapeutic options. This common disorder has high direct and indirect costs to the economic system. Frick et al. (6) reported financial losses greater than $\$ 2,000$ per patient annually due to absence from work and home management costs. Due to the excessive burden that this disorder places on both patients and healthcare systems, it is important to completely describe occurrence and risk factors associated with AUB in all populations, including the women most at risk because they live in underserved areas of the nation.

Other studies have demonstrated the disparities of care which occur in ethnic minorities and the access and management given in gynecological pathology in the USA (7-9). Descriptive studies of AUB subtype distribution in a population in the USA have never been performed. Our aim was to characterize the subset of patients who presented with AUB according to the FIGO classification in an underserved American metropolitan center.

\section{Material and Methods}

A descriptive cross-sectional analysis was conducted in an outpatient women's health clinic located in a medically underserved area of The Bronx, New York City, from November 2016 to December 2019. Our center is located in a high-volume, hospital-based clinic that serves $31 \%$ of the health care visits in the community where there is fewer than one primary care physician for every 4,000 people (10). The location has allowed access to a unique demographic of New York City's population, with some of the city's most ill and impoverished concentrated in its surrounding neighborhoods.

The study was approved by the Ethics Committee New York Health and Hospitals/Lincoln Institutional Review Board (approval number: $\mathrm{N}^{\circ}$ 19-034). Informed consent was not required because of the retrospective nature of the study, the research involved no more than minimal risk to the subjects and the waiver did not adversely affect the rights and welfare of the subjects.

Pregnant patients were excluded. Patients with AUB, defined as any variation from normal bleeding patterns lasting for a period of at least six months, were included. The AUB was further characterized according to the FIGO PALM-COEIN classification. The diagnosis was based on one or more of these investigations: history, physical examination, sonogram, hysteroscopy, dilatation and curettage, endometrial biopsy, and serum analyses. In addition, the following risk factors were recorded: age, body mass index (BMI), race and comorbidities.

\section{Statistical analysis}

Statistical analyses were performed using SPSS for Macintosh, version 27.0 (IBM Corp., Armonk, NY, USA). Continuous variables were expressed as median and interquartile range ( $25^{\text {th }}-75^{\text {th }}$ percentile). Categorical variables were expressed with number of cases/totals. The normality of the data was checked with the Kolmogorov-Smirnov normality test. None of the variables were normally distributed. Therefore, continuous variables were tested with the Mann-Whitney test and categorical variables with the chi-square test. A p-value $<0.05$ was considered statistically significant.

\section{Results}

Three hundred and ninety women were included in the study. The demographic characteristics of the study population, according to the FIGO AUB classification, are shown in Table 1. AUB-L was found to be the most common AUB type ( $n=185$, $47.4 \%)$, followed by AUB-P $(n=100,25.6 \%)$, AUB-A $(n=55$, $14.1 \%)$, AUB-O $(n=19,4.9 \%)$, AUB-M $(n=15,3.8 \%)$, AUB-E $(n=14,3.6 \%)$ and AUB-I $(n=2,0.5 \%)$. No cases of AUB-C and AUB-N were identified.

The median age was 47 (42-53) years old. The median BMI was 30.4 (27.6-34.9) kg/m².

Race was distributed as follows: Hispanic ( $n=266,68.2 \%)$, Black $(n=101,25.9 \%)$, Caucasian $(n=13,3.3 \%)$, and Asian $(n=8,2.1 \%)$ (Figure 1). Comorbidities were distributed as follows: hypertension $(n=142,36.4 \%)$, diabetes $(n=61,15.6 \%)$, and thyroid disease $(n=27,6.9 \%)$ (Figure 2$)$.

Table 2 shows the comparison of the minority AUB types to the majority type (AUB-L) in regard to BMI, age, and chronic medical conditions. The median age was significantly higher in AUB-P (52.5 years old, $\mathrm{p}<0.001$ ), AUB-M (59 years old, $\mathrm{p}<0.001$ ), AUB-E (51.5 years old, $\mathrm{p}=0.001$ ) compared to AUB-L (46 years old). The median BMI was significantly higher in AUB-O (32.6 $\left.\mathrm{kg} / \mathrm{m}^{2}, \mathrm{p}=0.038\right)$ and AUB-E $\left(34.2 \mathrm{~kg} / \mathrm{m}^{2}, \mathrm{p}=0.048\right)$ compared to AUB-L (30 kg/m²). Race and thyroid disease were equally distributed among the AUB types.

AUB-M (10/15, 66.6\%, p=0.002), AUB-E (8/14, 57.1\%, $\mathrm{p}=0.022)$, AUB-P $(47 / 100,47 \%, \mathrm{p}<0.001)$ and AUB-A $(17 / 55$, $30.9 \%, \mathrm{p}<0.001$ ) had statistically significantly more cases of hypertension compared to AUB-L (52/185, 28.1\%). AUB-E 
(5/14, 35.7\%, p=0.001), AUB-P (27/100, 27\%, p<0.001), AUB-M $(4 / 15,26.6 \%, \mathrm{p}=0.025)$ and AUB-A $(5 / 55,9 \%, \mathrm{p}<0.001)$ had a statistically higher number of patients with diabetes mellitus (DM) than AUB-L (13/390, 3.3\%).

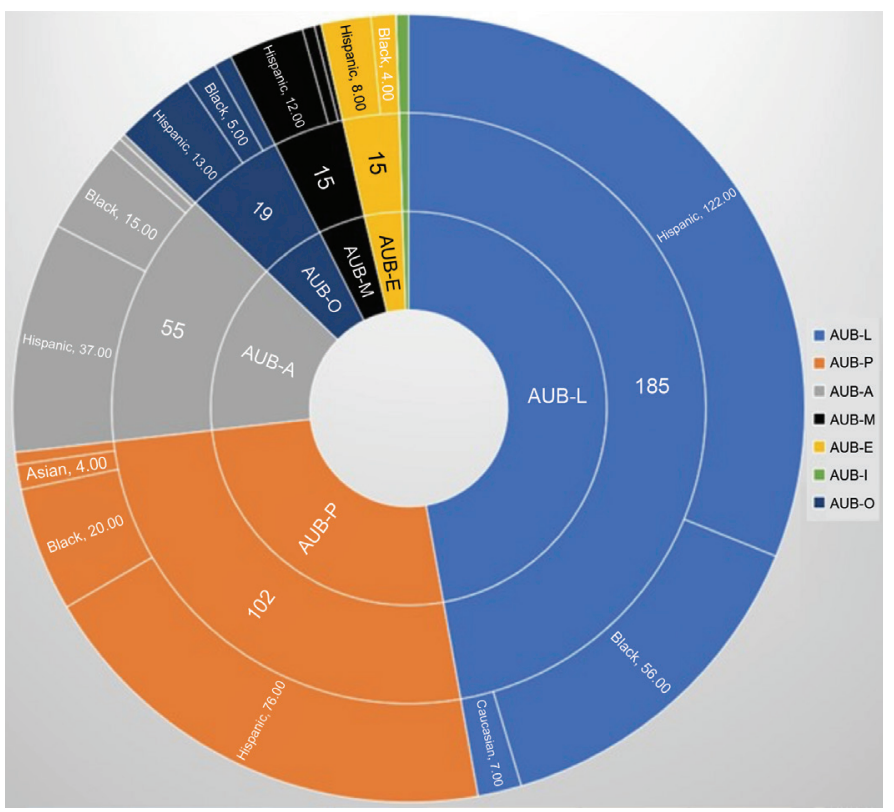

Figure 1. Distribution of races ethnicity (Hispanic, Black, Asian, Caucasian) according to AUB type (AUB-L, M, A, O, P, E, I)

AUB: Abnormal uterine bleeding, P: Polyp, A: Adenomyosis, L: Leiomyoma, M: Malignant lesion, O: Ovulatory dysfunction, E: Endometrial dysfunction, I: Iatrogenic

\section{Discussion}

In our study population, the most common type of AUB was AUB-L, followed by AUB-P, AUB-O, AUB-A, AUB-E, AUB-M and AUB-I. We did not find any case of AUB-C and AUB-N.

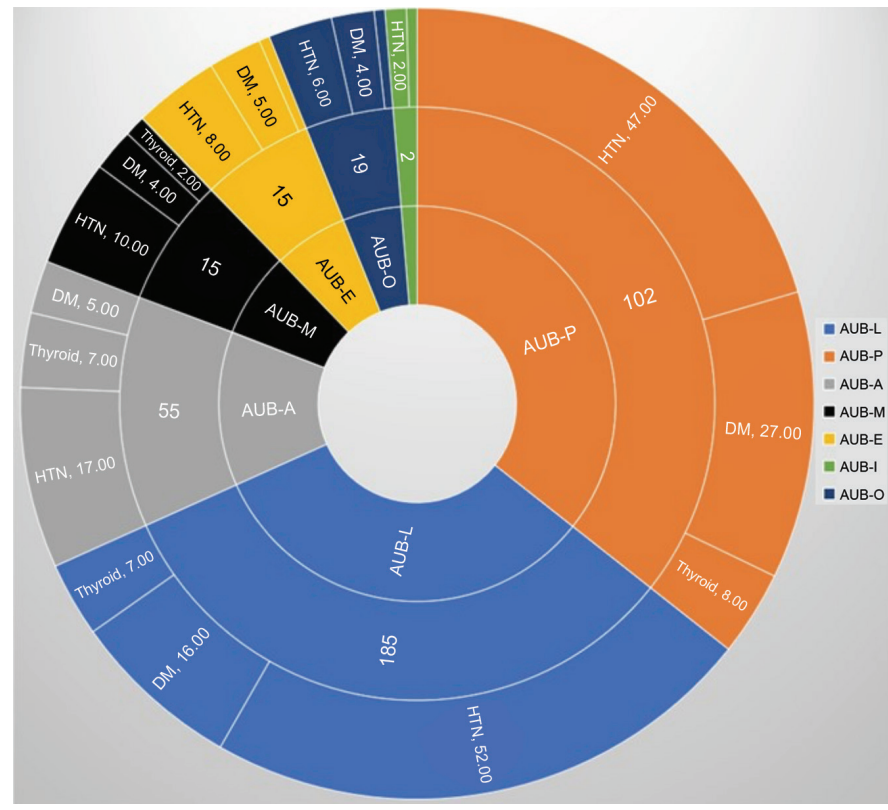

Figure 2. Distribution of comorbidities (HTN, Thyroid Disease, DM) according to AUB type (AUB-L, M, A, O, P, E, I) HTN: Hypertension, DM: Diabetes mellitus, AUB: Abnormal uterine bleeding, P: Polyp, A: Adenomyosis, L: Leiomyoma, M: Malignant lesion, O: Ovulatory dysfunction, E: Endometrial dysfunction, I: Iatrogenic

Table 1. Main characteristics of study population

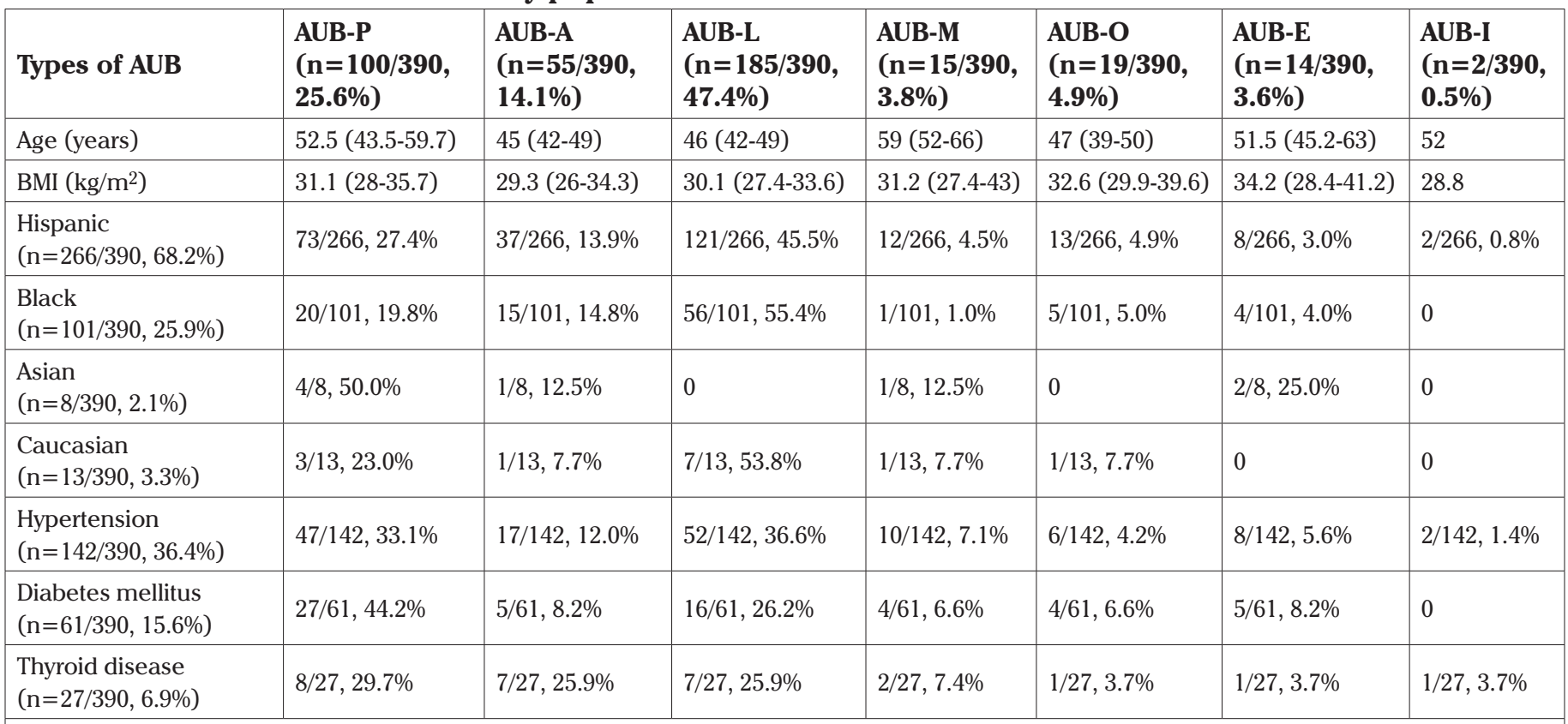

AUB: Abnormal uterine bleeding, P: Polyp, A: Adenomyosis, L: Leiomyoma, M: Malignant lesion, O: Ovulatory dysfunction, E: Endometrial dysfunction, I: Iatrogenic. BMI: Body mass index 
Table 2. Comparison of age, BMI, race and comorbidities between patients with AUB-L and the other types of AUB

\begin{tabular}{|c|c|c|c|c|c|c|}
\hline Types of AUB & $\begin{array}{l}\text { AUB-L } \\
(185 / 390,47.4 \%)\end{array}$ & $\begin{array}{l}\text { AUB-P } \\
(100 / 390,25.6 \%)\end{array}$ & $\begin{array}{l}\text { AUB-A } \\
(55 / 390,14.1 \%)\end{array}$ & $\begin{array}{l}\text { AUB-M } \\
(15 / 390,3.8 \%)\end{array}$ & $\begin{array}{l}\text { AUB-O } \\
(19 / 390,4.9 \%)\end{array}$ & $\begin{array}{l}\text { AUB-E } \\
(14 / 390,3.6 \%)\end{array}$ \\
\hline Age (years) & $45(38-56)$ & $\begin{array}{l}52.5(43.5-59.7) \\
\mathrm{p}<0.001 *\end{array}$ & $\begin{array}{l}45(42-49) \\
\text { NS* }\end{array}$ & $\begin{array}{l}59(52-56) \\
\mathrm{p}<0.001^{*}\end{array}$ & $\begin{array}{l}47(39-50) \\
\text { NS* }^{*}\end{array}$ & $\begin{array}{l}51.5(45.2-63) \\
p=0.01 *\end{array}$ \\
\hline BMI $\left(\mathrm{kg} / \mathrm{m}^{2}\right)$ & $30(25-39)$ & $\begin{array}{l}31.1(28-35.7) \\
\text { NS* }^{*}\end{array}$ & $\begin{array}{l}29.3(26-34.3) \\
\text { NS* }\end{array}$ & $\begin{array}{l}32.2(27.4-43) \\
\text { NS* }\end{array}$ & $\begin{array}{l}32.6(29.9-39.6) \\
\mathrm{p}=0.038 *\end{array}$ & $\begin{array}{l}34.2(28.4-41.2) \\
\mathrm{p}=0.048^{*}\end{array}$ \\
\hline $\begin{array}{l}\text { Race (number of } \\
\text { Hispanic/Black) }\end{array}$ & $\begin{array}{l}121 / 367,32.9 \% \mathrm{H} \\
56 / 367,15.2 \% \mathrm{~B}\end{array}$ & $\begin{array}{l}\text { 73/367, } 19.8 \% \mathrm{H} \\
20 / 367,5.4 \% \mathrm{~B} \\
\text { NS** }\end{array}$ & $\begin{array}{l}\text { 37/367, 10.0\% H } \\
15 / 367,4.0 \% \mathrm{~B} \\
\mathrm{NS}^{* *}\end{array}$ & $\begin{array}{l}12 / 367,3.2 \% \mathrm{H} \\
1 / 367,0.2 \% \mathrm{~B} \\
\text { NS** }\end{array}$ & $\begin{array}{l}\text { 13/367, 3.5\% H } \\
5 / 367,1.3 \% \mathrm{~B} \\
\mathrm{NS}^{* *}\end{array}$ & $\begin{array}{l}\text { 8/367, } 2.1 \% \mathrm{H} \\
4 / 367,1.0 \% \mathrm{~B} \\
\text { NS** }\end{array}$ \\
\hline $\begin{array}{l}\text { Hypertension } \\
\text { (number/total) }\end{array}$ & $53 / 390,13.6 \%$ & $\begin{array}{l}47 / 100,47.0 \% \\
p=0.001 * *\end{array}$ & $\begin{array}{l}17 / 55,31.0 \% \\
\mathrm{p}<0.001 * *\end{array}$ & $\begin{array}{l}10 / 15,66.7 \% \\
p=0.002^{* *}\end{array}$ & $6 / 19,31.6 \% \mathrm{NS}^{* *}$ & $\begin{array}{l}8 / 14,57.1 \% \\
p=0.022^{* *}\end{array}$ \\
\hline $\begin{array}{l}\text { Diabetes mellitus } \\
\text { (number/total) }\end{array}$ & $13 / 390,3.3 \%$ & $\begin{array}{l}27 / 100,27.0 \% \\
\mathrm{p}<0.001 * *\end{array}$ & $\begin{array}{l}5 / 55,9.0 \% \\
p<0.001 * *\end{array}$ & $\begin{array}{l}4 / 15,26.7 \% \\
p=0.025^{* *}\end{array}$ & $4 / 19,21.0 \% \mathrm{NS}^{* *}$ & $\begin{array}{l}5 / 14,35.7 \% \\
p=0.001 * *\end{array}$ \\
\hline $\begin{array}{l}\text { Thyroid disease } \\
\text { (number/total) }\end{array}$ & $10 / 390,2.6 \%$ & $\begin{array}{l}8 / 100,8.0 \% \\
N^{* * *}\end{array}$ & $\begin{array}{l}7 / 55,12.7 \% \\
\mathrm{NS}^{* *}\end{array}$ & $\begin{array}{l}2 / 15,13.3 \% \\
\text { NS** }^{* *}\end{array}$ & $\begin{array}{l}1 / 19,5.3 \% \\
\text { NS** }\end{array}$ & $\begin{array}{l}1 / 14,7.1 \% \\
\text { NS** }^{* *}\end{array}$ \\
\hline
\end{tabular}

\section{AUB-L}

Leiomyomas are benign monoclonal tumors of uterine smooth muscle tissue. They are the most common pelvic tumor in reproductive age women. The relationship between myomas and AUB is not completely known. Current knowledge suggests that cellular and molecular changes in myomatous tissue may impact on neo-angiogenesis and the release of growth factors (11).

In our study the prevalence of AUB-L was 56.4\%.

In 3 previous studies from India (12-14) the prevalence of AUB-L ranged from $24.6 \%$ to $30.4 \%$.

We think that the difference in prevalence between our study and the previous studies is related to the differences in demographics of the interested populations.

Indeed, our population was composed mainly of Hispanic and Black women, with a higher prevalence of uterine myomas than the Asian populations described in the previous studies.

\section{AUB-P}

Polyps are generated as endometrial outgrowths within the uterine cavity. Most polyps are diagnosed through transvaginal pelvic ultrasound. Histological examination is mandatory in order to exclude any malignancies (15).

In our study, polyp (AUB-P) was responsible for $25.6 \%$ of cases $(n=100)$.

Six previous studies from India and 1 from China reported a prevalence of AUB-P ranging from $2 \%$ to $16.2 \%$ (12-14,16-19).

Our prevalence of AUB-P was higher than the previous studies. The higher prevalence of AUB-P in our population could be caused by a wider use of hysteroscopy in Western countries.
Indeed, in our clinic hysteroscopy is readily available and widely used by the providers as one of the first diagnostic modalities of AUB.

\section{AUB-A}

Adenomyosis is characterized by the presence of endometrial glands and stroma locally or globally through the uterine musculature, causing hypertrophy of the surrounding myometrium. The pathogenesis of this disorder is not completely known. A diagnostic suspicion for this form of AUB-A can be prompted through a clinical history characterized by dysmenorrhea and diagnostic tools such as ultrasound or magnetic resonance. The definitive diagnosis is however obtained with histological examination after hysterectomy.

Our findings of 14\% AUB-A prevalence are in accordance with the previous literature on women from India and China. Indeed, a range of 4.9 to $20 \%$ of patients with AUB-A out of a total of patients with AUB is described in the previous literature (12-14,16-18).

\section{AUB-O}

We found 19/390 (4.9\%) with AUB-O. AUB-O is characterized by a persistent anovulatory state, ultimately leading to irregular endometrial tissue creation, which predisposes to abnormal sloughing of endometrial tissue and bleeding episodes. Ovulation is regulated by circulating levels of estrogen and progesterone, which have been strongly associated with differences in race (20). 
Sun et al. (19), in 2018, found that the main cause of AUB in 1053 Chinese women in hospital settings, aged 15 to 55 years, was ovarian dysfunction $(n=608,57.7 \%)$. In 2020, Seetha et al. (16) found that ovulation impairment represented the most common cause of AUB, 99 patients (28.2\%) after analyzing 350 women of age range 18-45 years old in India. Goel and Rathore (18) in 2016 analyzed 300 patients with no age restriction, from India, with AUB and found AUB-O to be the most prevalent with 85 cases (28.3\%). The differences of AUB-O prevalence between our study and the studies by Sun et al. (19), Seetha et al. (16), and Goel and Rathore (18) might be due to differences in population demographics or the settings of the studies with some based in inpatient populations and some in outpatient populations. In fact, only $2.5 \%$ of our total study population was of Asian race; the race distribution was not described in Sun et al. (19) and Seetha et al.'s (16), studies but they were both conducted in geographic areas from Asia.

\section{AUB-M}

We found 15 women out of 390 (3.8\%) affected by AUB-M. AUB-M is mainly caused by cancers of the uterus. Endometrial cancer, the most recurrent cause of AUB-M, represents the fourth most common cancer in the USA after breast, lung and colon cancers (21). Several risk factors have been associated with endometrial cancer, such as race, nulliparity, estrogen therapy, early menarche, delayed menopause and Lynch syndrome. However, obesity, hypertension and diabetes are also implicated as important in the pathogenesis of endometrial cancer. Our results were at the lower end of the range reported in the previous literature where the prevalence of AUB-M ranges from 1.9\% to $21.6 \%(12-14,16-19)$.

\section{AUB-E}

In our study, we found a total of 14/391 (3.6\%) with AUB-E. AUB-E are intrinsic endometrial causes of abnormal bleeding. The diagnosis of AUB-E is reached when other pathologies are excluded either by imaging or histological sampling in the setting of normal ovulatory function.

Gubbala and Mattaparti (17) in 2019 in India studying a population up to 75 years old found that AUB-E was the most common AUB subtype, with $41.9 \%$ of the cases. Gubbala and Mattaparti (17) obtained a histopathological sample for each of their patients. On the contrary, in our study the endometrial samples were obtained only at the clinician's discretion and this could be the reason for the different prevalence of AUB-E between our findings and the study of Gubbala and Mattaparti (17).

\section{AUB-I}

We found two patients with AUB-I, out of 390 total patients $(0.5 \%)$. They were both over 50 years old, Hispanic, and both had hypertension. Both of them were on medications to treat breast cancer and the AUB manifested as a side effect of these medications. The AUB-I promptly resolved once the medications were discontinued. Our prevalence result of AUB-I is below the prevalence range found in the literature, ranging from $1 \%$ to $11.6 \%(12-14,16,18,19)$.

We speculate that the difference between our study and the previous literature may be biased by an under reporting by our providers of AUB-I in our electronic medical records (EMR) system.

\section{Differences of comorbidities among AUB types}

In our population, AUB-O and AUB-E had higher BMI than AUB-L. This is likely the results of unopposed estrogen from increased adipose reserves and its effect on both ovulation and the endometrium.

In regard to analysis of age in the population, AUB-P, AUB-M, AUB-E were significantly older than AUB-L. This may be due to the pathogenesis of these specific disorders and the propensity to develop in an older population. The results of our study indicated that hypertension was the most prevalent chronic medical co-morbidity in our patients $(n=142,36.4 \%)$, then DM $(n=61,15.6 \%)$ and then thyroid disease $(n=27,6.9 \%)$ for all the considered groups of AUB type.

AUB-P, AUB-A, AUB-M and AUB-E had statistically significantly more cases of hypertension compared to AUB-L. This might be the effect of hypertension as predominant comorbid condition in advanced ages as these AUB types are seen in that age demographic. The study demonstrated a higher number of AUB-P, AUB-M, AUB-A, and AUB-E patients with DM compared to AUB-L. We speculate that the higher age of AUB-P, AUB-M, AUB-A and AUB-E, compared to AUB-L, likely plays a role in the increased prevalence of DM. Indeed, diabetes and disorders of insulin resistance are chronic medical conditions seen more in geriatric and obese populations. From our analysis, race differences and distribution of thyroid disease were equally distributed among the AUB types.

\section{Study Strengths and Limitations}

One of the strengths of our study is that it is the first study to describe the distribution of AUB subtypes according to the FIGO PALM-COEIN classification in an urban underserved American population, to our knowledge. The absence of AUB-C and AUB-N in our population might be biased by limitations of our EMR system. The study was also limited in the range of comorbidities which could be assessed in relation to the AUB types. Due to limitations in how these are able to be analyzed 
in the EMR system, only some of the medical comorbidities (hypertension, diabetes and thyroid disease) were collected.

The comparison between this study and other previous studies was difficult in analyzing the distribution of risk factors among AUB types, as they were all heterogeneous regarding age range, time frame, setting, associated factors and diagnostic investigations.

\section{Conclusion}

This study serves as a pilot analysis into prevalence of AUB types and chronic medical conditions in minority populations of an inner-city population in the USA. Our finding revealed that leiomyoma represented the most common cause of AUB while the most common race was Hispanic. Moreover, women affected by leiomyoma were younger, with lower BMI and with lower incidence of hypertension and DM when compared to other types of AUB. Future studies are needed to stratify the management options for AUB in these select populations.

Ethics Committee Approval: The study was approved by the Ethics Committee New York Health and Hospitals/Lincoln Institutional Review Board (approval number: 19-034).

Informed Consent: This was not required because of the retrospective nature of the study; the research involves no more than minimal risk to the subjects and the waiver will not adversely affect the rights and welfare of the subjects.

Peer-review: Externally peer-reviewed.

Author Contributions: Surgical and Medical Practices: A.Sa., G.S.; Concept: A.Sa., G.S.; Design: L.S., D.N.; Data Collection or Processing: L.S., G.S.; Analysis or Interpretation: A.S., G.S.; Literature Search: A.S., L.S.; Writing: A.Sa., A.S., A.S.

Conflict of Interest: No conflict of interest is declared by the authors.

Financial Disclosure: The authors declared that this study received no financial support.

\section{References}

1. Munro MG, Critchley HOD, Fraser IS, FIGO Menstrual Disorders Committee. The two FIGO systems for normal and abnormal uterine bleeding symptoms and classification of causes of abnormal uterine bleeding in the reproductive years: 2018 revisions. Int $\mathrm{J}$ Gynaecol Obstet 2018; 143: 393-408.

2. Whitaker L, Critchley HOD. Abnormal uterine bleeding. Best Pract Res Clin Obstet Gynaecol 2016; 34: 54-65.

3. Davis E, Sparzak PB. Abnormal Uterine Bleeding. 2021 Feb 10. In: StatPearls [Internet]. Treasure Island (FL): StatPearls Publishing; 2021.
4. Committee on Practice Bulletins-Gynecology. Practice bulletin no. 128: diagnosis of abnormal uterine bleeding in reproductive-aged women. Obstet Gynecol 2012; 120: 197-206.

5. Munro MG, Critchley HO, Broder MS, Fraser IS; FIGO Working Group on Menstrual Disorders. FIGO classification system (PALM-COEIN) for causes of abnormal uterine bleeding in nongravid women of reproductive age. Int J Gynaecol Obstet 2011; 113: 3-13.

6. Frick KD, Clark MA, Steinwachs DM, Langenberg P, Stovall D, Munro MG, et al; STOP-DUB Research Group. Financial and quality-of-life burden of dysfunctional uterine bleeding among women agreeing to obtain surgical treatment. Womens Health Issues 2009; 19: 70-8.

7. Patel SN, Staples JN, Garcia C, Chatfield L, Ferriss JS, Duska L. Are ethnic and racial minority women less likely to participate in clinical trials? Gynecol Oncol 2020; 157: 323-8.

8. Kaspers M, Llamocca E, Quick A, Dholakia J, Salani R, Felix AS. Black and Hispanic women are less likely than white women to receive guideline-concordant endometrial cancer treatment. Am J Obstet Gynecol 2020; 223: 398.e1-398.e18.

9. Schlumbrecht M, Cerbon D, Castillo M, Jordan S, Butler R, Pinto A, et al. Race and ethnicity influence survival outcomes in women of caribbean nativity with epithelial ovarian cancer. Front Oncol 2020; 10: 880.

10. Lincoln Medical and Mental Health Center. Predoctoral Psychology Internship Program [Internet]. LINCOLN; 2020.

11. Lasmar RB, Lasmar BP. The role of leiomyomas in the genesis of abnormal uterine bleeding (AUB). Best Pract Res Clin Obstet Gynaecol 2017; 40: 82-8.

12. Betha K, Malavatu L, Talasani S. Distribution of causes of abnormal uterine bleeding using new FIGO classification system-PALM COEIN: a rural tertiary hospital based study. Int J Reprod Contracept Obstet Gynecol 2017; 6: 3523-7.

13. Ratnani R, Meena N. A Clinico-pathological analysis of causes of abnormal uterine bleeding according to PALM -COEIN classification: Study based in a Rural Teaching Hospital of Central India. J Med Sci Clin Res 2017; 5: 28196-200.

14. Gouri SRS, Lakshmi PV, Rani NG Kumar NA. Categorization of the causes of abnormal uterine bleeding according to PALM-COEIN classification. Int J Sci Stud 2016; 4: 104-7.

15. De Franciscis P, Riemma G, Schiattarella A, Cobellis L, Guadagno M, Vitale SG, et al. Concordance between the hysteroscopic diagnosis of endometrial hyperplasia and histopathological examination. Diagnostics (Basel, Switzerland). 2019; 9: 142.

16. Seetha PM, Venetia A, Haridas N. A study on distribution of causes of non-gestational AUB in reproductive age group as per the FIGO classification in a tertiary care centre. Int J Clin Obstet Gynaecol 2020; 4: 84-7.

17. Gubbala SDD, Mattaparti DS. Clinico-pathological evaluation and etiological stratification of chronic AUB patients based on PALMCOEIN classification: A prospective study in tertiary care center of Nalgonda District. Int J Clin Diagnostic Pathol 2019; 2: 174-81.

18. Goel P, Rathore SB. PALM-COEIN FIGO Classification for diagnosis of abnormal uterine bleeding: Practical Utility of same at Tertiary Care Centre in North India. 2016; 4: 2771-3.

19. Sun Y, Wang Y, Mao L, Wen J, Bai W. Prevalence of abnormal uterine bleeding according to new International Federation of Gynecology and Obstetrics classification in Chinese women of reproductive age: A cross-sectional study. Medicine (Baltimore) 2018; 97: e1 1457.

20. Haiman CA, Pike MC, Bernstein L, Jaque SV, Stanczyk FZ, Afghani $\mathrm{A}$, et al. Ethnic differences in ovulatory function in nulliparous women. Br J Cancer 2002; 86: 367-71.

21. La Rosa VL, Garzon S, Gullo G, Fichera M, Sisti G, Gallo P, et al. Fertility preservation in women affected by gynaecological cancer: the importance of an integrated gynaecological and psychological approach. Ecancermedicalscience 2020; 14: 1035. 